\title{
Mucin-like peptides from Echinococcus granulosus induce antitumor activity
}

\author{
VERÓNICA NOYA $^{1}$, SYLVIE BAY ${ }^{2,3}$, MARÍA FLORENCIA FESTARI ${ }^{1,4}$, ENRIQUE P. GARCÍA ${ }^{1}$, \\ ERNESTO RODRIGUEZ ${ }^{1}$, CAROLINA CHIALE ${ }^{1}$, CHRISTELLE GANNEAU ${ }^{2,3}$, FRANÇOISE BALEUX ${ }^{2,3}$, \\ SOLEDAD ASTRADA $^{5}$, MARIELA BOLLATI-FOGOLÍN ${ }^{5}$, EDUARDO OSINAGA $^{1,4}$ and TERESA FREIRE ${ }^{1,4}$ \\ ${ }^{1}$ Department of Immunobiology, School of Medicine, UdelaR, 11800 Montevideo, Uruguay; ${ }^{2}$ Department of Structure \\ and Chemical Biology, Unit of Biomolecule Chemistry, Institut Pasteur, 75724 Paris Cedex 15; ${ }^{3}$ CNRS UMR 3523, \\ 75015 Paris, France; ${ }^{4}$ Laboratory of Tumor Glycobiology and Immunology, ${ }^{5}$ Cell Biology Unit, \\ Institut Pasteur Montevideo, Mataojo 2020, 11400 Montevideo, Uruguay
}

Received April 8,2013; Accepted May 30, 2013

DOI: 10.3892/ijo.2013.2000

\begin{abstract}
There is substantial evidence suggesting that certain parasites can have antitumor properties. We evaluated mucin peptides derived from the helminth Echinococcus granulosus (denominated Egmuc) as potential inducers of antitumor activity. We present data showing that Egmuc peptides were capable of inducing an increase of activated NK cells in the spleen of immunized mice, a fact that was correlated with the capacity of splenocytes to mediate killing of tumor cells. We demonstrated that Egmuc peptides enhance LPS-induced maturation of dendritic cells in vitro by increasing the production of IL-12p40p70 and IL-6 and that Egmuc-treated DCs may activate NK cells, as judged by an increased expression of CD69. This evidence may contribute to the design of tumor vaccines and open new horizons in the use of parasite-derived molecules in the fight against cancer.
\end{abstract}

\section{Introduction}

Several infectious agents (e.g. the bacterium Helicobacter pylori, the human papilloma viruses and the hepatitis $\mathrm{B}$ and $\mathrm{C}$

Correspondence to: Dr Teresa Freire, Department of Immunobiology, School of Medicine, UdelaR, Gral. Flores 2125, 11800 Montevideo, Uruguay

E-mail: tfreire@fmed.edu.uy

Abbreviations: APC, antigen presenting cells; BMDCs, bone marrow derived dendritic cells; DCs, dendritic cells; NK, natural killer; LN, lymph node; PRR, pattern recognition receptors; TLR, Toll-like receptor; NLR, Nod-like receptor; PAMP, pathogenassociated molecular patterns; CFA, complete Freund adjuvant; CPM, counts per minute; Ig, immunoglobulin; MHC, major histocompatibility complex; MGL, macrophage Gal/GalNAc lectin; SD, standard deviation; nd, not done

Key words: Echinococcus granulosus, cancer, dendritic cell, immunotherapy, mucin, NK cell, peptide viruses) are considered to be causes of cancer in humans (1). Of the 12.7 million new cancer cases that occurred in 2008, $16.1 \%$ were attributed to infections (2). Among parasites, a carcinogenic role is recognized to Schistosoma haematobium (leading to bladder cancer) and to Clonorchis sinensis or Opisthorchis viverrini (which cause cholangiocarcinoma) (3). By contrast, there is increasing evidence indicating that certain parasitic infections may induce antitumor activity against cancer. For instance, infection of animals with the protozoans Trypanosoma cruzi (4) or Plasmodium yoelii (5) as well as the nematode Trichinella spiralis (6), protected from tumor growth. In the latter case, the tumor protection was also obtained in mice immunized with crude extracts from adult parasites (6). Interestingly, an epidemiological investigation on patients with cancer demonstrated a negative correlation between cancer and hydatic cyst infection (7). It has been recently reported that hydatid cyst protoscolices inhibited the proliferation of fibrosarcoma cells in vitro (8). Collectively the evidence suggests that some helminths may have antitumor properties.

It has been recently hypothesized that chronic parasite infections may raise non-specific innate immune responses that might induce anticancer activity (9). In this context, dendritic cells (DCs), among other cells, recognize pathogens through a variety of pattern recognition receptors (PRR) including Toll-like receptors (TLR), C-type lectins (CLR) and intracellular Nod-like receptors (NLR) (10). Thus, DCs can trigger innate lymphocyte-functions, including natural killer (NK) cells and regulate $\mathrm{T}$ and $\mathrm{B}$ cell responses (11). In particular, several molecules produced by helminths have been described to interact with DCs through TLRs or CLRs, modulating their maturation or function (12-15).

Certain helminth parasites express $O$-glycans and mucinlike molecules, the major carriers of $O$-glycans (16-18). They participate in attachment and invasion of host cells among other processes, by providing proteases resistance or avoiding immune recognition $(18,19)$. In particular, the presence of tumor-associated antigens, such as Tn (GalNAc$O$-Ser/Thr), has been reported in larval and adult tissues of 
Echinococcus granulosus, as well as circulating Tn antigen in hydatid patients (20).

Aberrantly glycosylated mucins, carrying Tn among others, are overexpressed in a wide range of epithelial human cancers $(21,22)$ and have functional importance in cell adhesion, invasion and metastasis $(23,24)$. These properties make them relevant targets for the prevention of metastasis and recurrence of cancers by therapeutic vaccination $(25,26)$. A number of antitumor vaccines based on mucins have been developed and tested in preclinical models (25). However, several clinical trials using this type of vaccines together with different carriers and/or adjuvant, did not exhibit sufficient efficacy, except for some specific settings (27-29). The low efficacy of these trials could be attributed to a poor capacity to break immune-tolerance to mucin epitopes, which are usually self-antigens.

Taking into account the data reporting that the helminth E. granulosus induce antitumor cell activity and that human mucins play main roles in tumor invasiveness, we sought to evaluate whether peptides derived from a mucin-like protein from this parasite would induce antitumor immunity. During a characterization of the transcriptome of E. granulosus larval stages (30) a cDNA clone coding for a mucin-like protein has been isolated. The predicted protein, denominated Egmuc, has a total of 58 amino acids, 23 of which are threonine or serine residues that constitute potential $O$-glycosylation sites. The fact that Egmuc comes from an evolutionary distant organism should overcome tolerance issues encountered with humanmucin based cancer therapeutic approaches.

In the present study, we show that the Egmuc peptide, as well as its $\mathrm{CD} 4^{+} \mathrm{T}$ cell epitope, provide splenocytes with the capacity to mediate killing of tumor cells. We also show that this property is correlated with an increase of activated NK cells in spleen. We demonstrate that Egmuc peptides induce, together with LPS, maturation of DCs by increasing the production of IL-12 and IL- 6 and that Egmuc-treated DCs may activate NK cells, as judged by an increased expression of CD69. In addition, the obtained results were compared to the ones induced by a glycosylated peptide form carrying two consecutive Tn antigens. We show that glycosylation of Egmuc does not increase the antitumor activity induced by non-glycosylated Egmuc peptides. Our data may contribute to the design of tumor vaccines and open new horizons in the use of parasite-derived molecules to fight against cancer.

\section{Materials and methods}

Mice. Six- to 8-week-old female C57BL/6 or BALB/c mice were obtained from DILAVE Laboratories (Uruguay). Animals were kept in the animal house (URBE, School of Medicine, UdelaR, Uruguay) with water and food supplied ad libitum and handled in accordance with institutional guidelines for animal welfare [Comisión Honoraria de Experimentación Animal (CHEA), Uruguay].

Egmuc peptides and glycopeptide. A 58-amino acid sequence of a E. granulosus mucin like-protein, named Egmuc and 15 mer-peptides, overlapping by five amino acids and spanning the Egmuc sequence were synthesized as previously described (31) or by SBS Bio Beijing SBS Genetech Co. Ltd. (China) or Peptide 2.0 Inc. (USA). The amino acid sequences of the peptides are detailed in Fig. 1B. Egmuc $33-47-2 \mathrm{Tn}$ glycopeptide was produced by solid-phase synthesis as previously described (32). All the (glyco)peptides were quantified by amino acid analysis and characterized by electrospray mass spectrometry. Atto-647N labeling of peptides and glycopeptide with NHS ester was performed according to the instructions of the manufacturer (Fluka, USA).

Endotoxin level determination. The endotoxin level of synthetic peptides and glycopeptide was determined according to the instructions of the manufacturer, using the Limulus Amebocyte Lysate kit Pyrochrome (Associates of Cape Cod). Egmuc peptides and glycopeptide showed very low levels of endotoxins ( $<1.6 \mathrm{EU} / \mathrm{mg}$ protein).

Cell lines. The C57BL/6 syngeneic pancreatic tumor cell line Panc02 (given by Dr R. Hernandez-Alcoceba, University of Navarra, Pamplona, Spain) and the BALB/c syngeneic mammary adenocarcinoma cell line TA3/Ha (provided by Professor C. Leclerc, Institut Pasteur, Paris, France) were cultured in complete culture medium, consisting of RPMI-1640 with glutamine (PAA Laboratories, Austria) supplemented with $10 \%$ heat-inactivated fetal bovine serum, $50 \mu \mathrm{M}$ 2-mercaptoethanol, $100 \mathrm{U} / \mathrm{ml}$ penicillin (Sigma, St. Louis, MO, USA), $100 \mathrm{mg} / \mathrm{ml}$ streptomycin (Sigma), at $37^{\circ} \mathrm{C}$ and $5 \% \mathrm{CO}_{2}$.

$T$ cell response. Mice were s.c. immunized at the base of the tail with Egmuc, Egmuc $33-47$ or Egmuc $_{33-47}-2 \mathrm{Tn}(20 \mu \mathrm{g}$ or 10 nmoles/mouse depending on the experiment) in complete Freund adjuvant (CFA). Inguinal lymph nodes (LN) from control or Egmuc, Egmuc $33-47$ or Egmuc $_{33-47}-2 \mathrm{Tn}$ immunized mice were removed after 10 days and the cells were dispersed manually and centrifuged at $1,500 \mathrm{rpm}$ for $5 \mathrm{~min}$. Cells (1) $10^{6} /$ well) were suspended in complete culture medium and cultured for $72 \mathrm{~h}$ at $37^{\circ} \mathrm{C}$ and $5 \% \mathrm{CO}_{2}$ in 96-well plates with Egmuc peptide, overlapping 15 amino acids peptides or glycopeptide $(10 \mu \mathrm{M})$ and with TA3/Ha or Panc02 lysates $(250 \mu \mathrm{g} /$ $\mathrm{ml}$ ). They were then pulsed with $\left[{ }^{3} \mathrm{H}\right]$-thymidine (American Radiolabeled Chemicals Inc., St. Louis, MO, USA) for the last $18 \mathrm{~h}$ of culture and harvested by an automated cell harvester (Tomtec). Proliferation was determined by incorporation of the radioactivity by the cells and the results (expressed in counts per minute, $\mathrm{cpm}$ ) represent the means of triplicate determinations. Controls were incubated either with culture medium alone or with concanavalin A $(10 \mu \mathrm{g} / \mathrm{ml})$. The negative control group consisted of mice immunized with an irrelevant peptide corresponding to a sequence of a human mucin MUC6 (PLITVTTSRTSQVHS). Secreted cytokines (IFN $\gamma$, IL-5 and IL-17) levels were tested on culture supernatants by interleukin specific sandwich ELISA assays (BD Bioscience, NJ, USA). Results are expressed in $\mathrm{pg} / \mathrm{ml}$.

Cytotoxic in vitro assays. Mice were immunized i.p. with Egmuc, Egmuc $33-47$, Egmuc $_{33-47}-2 \mathrm{Tn}$ (10 nmoles/mouse) or PBS in complete or incomplete Freund's adjuvant, at days 0, 14 and 28. Splenocytes from Egmuc peptides or glycopeptide and control immunized mice were removed after 35 days and the cells were dispersed manually and centrifuged at $1,500 \mathrm{rpm}$ for 
A
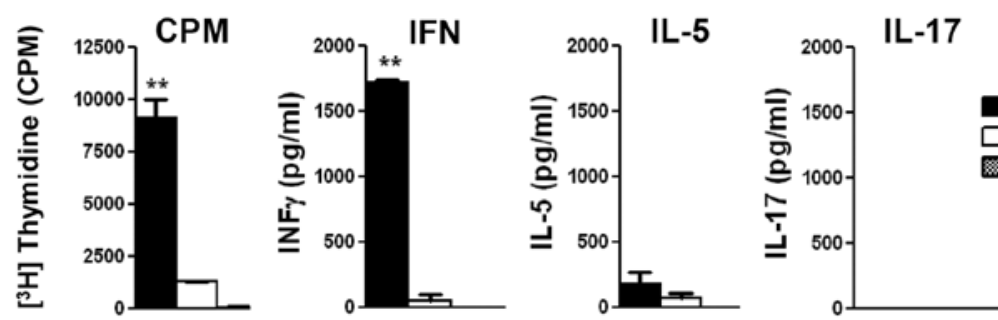

Egmuc

Irrelevant peptide

Egmuc

空
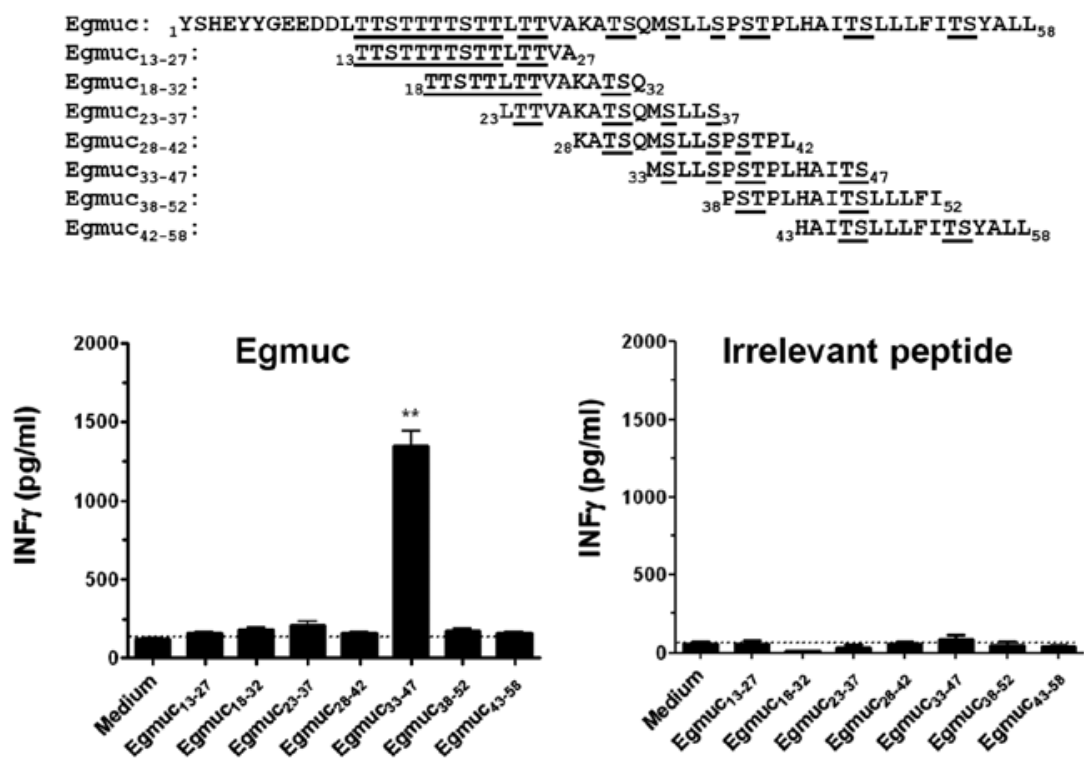

C
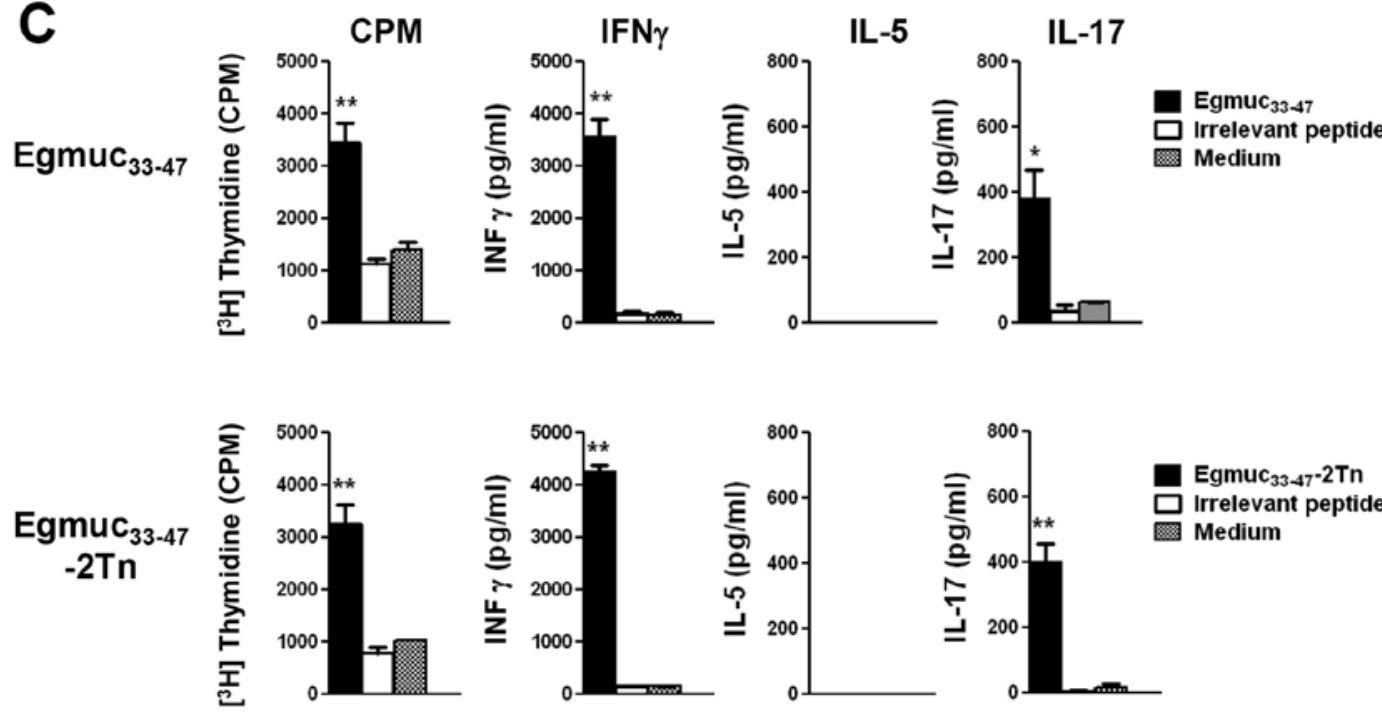

Figure 1. Egmuc and the immunodominant peptide Egmuc $_{33-47}$ induce high production of IFN $\gamma$. (A) C57BL/6 mice (5 per group) were immunized subcutaneously with $20 \mu \mathrm{g}$ of Egmuc in CFA. After 10 days, inguinal lymph node cells were cultured in triplicates in the presence of $10 \mu \mathrm{M}$ of Egmuc, an irrelevant peptide or medium alone for $72 \mathrm{~h}$ at $37^{\circ} \mathrm{C}$. Cell proliferation was evaluated according to the incorporation of $\left[^{3} \mathrm{H}\right]$-thymidine (CPM). Culture supernatants were collected and analyzed by ELISA for IFN $\gamma$, IL-5 and IL-17. Results are expressed as mean value of triplicates ( \pm SD, indicated by error bars) and are representative of three different experiments. Asterisks $(* *)$ represent differences statistically significant $(\mathrm{p}<0.01)$ with respect to medium. (B) C57BL/6 mice ( 5 per group) were immunized subcutaneously with Egmuc ( $20 \mu \mathrm{g} /$ mouse) or an irrelevant peptide in CFA. Ten days later, cells obtained from draining LN were pooled and cultured in triplicate in the presence of a set of synthetic overlapping peptides contained within the Egmuc sequence (panel in the top), Egmuc or the irrelevant peptide (not shown). INF $\gamma$ production was evaluated by ELISA. (C) C57BL/6 mice (5 per group) were immunized subcutaneously with Egmuc $33-47$ or Egmuc $33-47-2 \mathrm{Tn}(20 \mu \mathrm{g} /$ mouse $)$ in CFA. After 10 days, cells from inguinal LN were cultured in triplicates for $72 \mathrm{~h}$ in the presence of the respective peptide or glycopeptide, as well as an irrelevant peptide $(10 \mu \mathrm{M})$ or medium alone. Cell proliferation was evaluated according to the incorporation of [ $\left.{ }^{3} \mathrm{H}\right]$-thymidine (CPM). Culture supernatants were collected and analyzed by ELISA for INF $\gamma$, IL-5 and IL-17 production. Results are expressed as mean value of triplicates $\left( \pm \mathrm{SD}\right.$, indicated by error bars) and are representative of three different experiments. Asterisks $(* *)$ represent statistically significant differences $\left({ }^{* *} \mathrm{p}<0.01\right.$, * $\mathrm{p}<0.05)$ with respect to medium. 
5 min. Effector splenocytes (E) and target (T) TA3/Ha or Panc02 cells were cultured in different ratios for $18 \mathrm{~h}$ at $37^{\circ} \mathrm{C}$ and $5 \% \mathrm{CO}_{2}$ in 96-well plates in complete culture medium. Then, $10 \mu \mathrm{l} /$ well of WST-8 (2-(2-methoxy-4-nitrophenyl)-3-(4-nitrophenyl)-5(2,4-disulfophenyl)-2H-tetrazolium (Sigma-Aldrich, St. Louis, MO, USA) were added to the media and incubated for $3 \mathrm{~h}$ at $37^{\circ} \mathrm{C}$ and $5 \% \mathrm{CO}_{2}$. Absorbance at $450 \mathrm{~nm}$ was measured each hour using an ELISA autoscan (Labsystems Multiskan MS). Each condition was analyzed in triplicates. Controls were carried out by culturing tumor cells alone, splenocytes alone and tumor cells in presence of $1 \%$ Triton X-100 containing media ( $100 \%$ of expected cytotoxicity). Percentage of cytotoxicity was calculated as: $\%$ cytotoxicity $=\left[\mathrm{E}_{\text {alone }}+\mathrm{T}_{\text {alone }}-(\mathrm{E}+\mathrm{T})\right]$ / $\left(\mathrm{T}_{\text {alone }}-\mathrm{T}_{\text {Triton X-100) }}\right)$, where E corresponds to splenocytes and $\mathrm{T}$ are tumor cells.

Generation of bone marrow-derived dendritic cells (BMDCs). BMDCs were generated from bone marrow precursors from C57BL/6 mice. Briefly, bone marrow cells from femurs and tibias were harvested and plated at a density of $2 \times 10^{5}$ cells/ $\mathrm{ml}$ in complete culture medium supplemented with GM-CSFcontaining supernatant. After 3 days of culture at $37^{\circ} \mathrm{C}$, the medium was replaced. Cells were recovered on day 6 or 7 and analyzed for the expression of CD11c by flow cytometry.

In vitro internalization assay. The in vitro internalization of Egmuc peptides or glycopeptide was analyzed by confocal microscopy and flow cytometry. BMDCs were incubated $(2.5$ $\mathrm{x} 10^{5} /$ well) with Atto- $647 \mathrm{~N}$-labeled antigens for $1 \mathrm{~h}$ at $37^{\circ} \mathrm{C}$ in complete medium (to assess uptake), or at $4^{\circ} \mathrm{C}$ in complete medium (to assess binding). Cells were then washed twice and analyzed by flow cytometry. Alternatively, cells were fixed with $1 \%$ formaldehyde and dried over glass slides. Cells were then stained with anti-mouse Lamp-1 (eBioscience, CA, USA) followed by an anti-rat IgG TRITC-conjugated antibody (eBioscience) and with anti-mouse CD11c antibody FITC-conjugated. All images were taken using laser confocal microscope Leica TCS SP5 and a 63x oil objective. Four optical sections scanned at intervals of $0.5 \mu \mathrm{m}$ were projected using Maximun Intensity Model using LASAF Lite. $2.6 .0 \mathrm{v}$ software.

BMDC maturation. BMDCs were incubated $\left(2.5 \times 10^{5} /\right.$ well) at $37^{\circ} \mathrm{C}$ and $5 \% \mathrm{CO}_{2}$ in 96-well plates with Egmuc, Egmuc ${ }_{33-47}$, Egmuc $_{33-47}-2 \operatorname{Tn}(10 \mu \mathrm{M})$ or medium alone for $1 \mathrm{~h}$. After $2 \mathrm{~h}$, cells were stimulated with LPS $(1 \mu \mathrm{g} / \mathrm{ml})$ and incubated overnight at $37^{\circ} \mathrm{C}$ and $5 \% \mathrm{CO}_{2}$. Cells were centrifuged at $1,500 \mathrm{rpm}$ for $5 \mathrm{~min}$ at $4^{\circ} \mathrm{C}$ and supernatants were then collected. Cytokine (IL-12p40p70, IL-10 and IL-6) levels were tested on culture supernatants by interleukin specific sandwich ELISA assays (BD Bioscience). Results are expressed in $\mathrm{pg} / \mathrm{ml}$.

Phenotypic analyses of loaded BMDC were evaluated by flow cytometry. Briefly, cells were incubated for $15 \mathrm{~min}$ at $4^{\circ} \mathrm{C}$ with fluorochrome-conjugated antibodies: CD86 (GL-2), CD40 (HM40-3), CD80 (16-10A1) and MHC II (M5/114.15.2) (eBioscience) and fixed with $0.1 \%$ formaldehyde.

Analysis of splenocytes by flow cytometry. Splenocytes, from Egmuc peptides or glycopeptide and control-immunized mice obtained as described above, were washed twice with PBS containing $2 \%$ FBS and $0.1 \%$ sodium azide. Splenocytes were then stained with an anti-NK1.1-PE (PK136), antiCD69-FITC (H1.2F3) and CD49b-APC (DX5), to identify activated NK cells. Cells were then washed twice with PBS containing 5\% FBS and $0.1 \%$ sodium azide and fixed with $1 \%$ formaldehyde. Cell populations were analyzed using a CyAn ADP Analyzer (Beckman Coulter). Other antibodies used in this study included: CD11b (M1/70), CD11c (N418), CD3 (17A2), CD103 (2E7), CD4 (RM4-5), CD8 $\alpha$ (53-6.7), CD40 (HM40-3), I-A/I-E (2G9), F4/80 (BM8), MHC II (m5/114.15.2), Ly-6G (RB6-8C5), Ly-6C (HK1.4), CD25 (PC61.5), FoxP3 (FJK-16s), CD19 (eBio1 D3), obtained from eBioscience.

In vitro analysis of the activation of $N K$ cells by Egmuctreated BMDCs. BMDCs were incubated $\left(2.5 \times 10^{5} /\right.$ well $)$ at $37^{\circ} \mathrm{C}$ and $5 \% \mathrm{CO}_{2}$ in 96-well plates with Egmuc, Egmuc E3-47 $_{3}$, Egmuc $_{33-47}-2 \mathrm{Tn}$ or medium alone for $1 \mathrm{~h}$. After $2 \mathrm{~h}$, cells were stimulated with LPS $(1 \mu \mathrm{g} / \mathrm{ml})$ and incubated overnight at $37^{\circ} \mathrm{C}$ and $5 \% \mathrm{CO}_{2}$. Cells were then centrifuged at $1,500 \mathrm{rpm}$ for $5 \mathrm{~min}$ at $4^{\circ} \mathrm{C}$ and supernatants were then collected. Splenocytes (1×10\% $/$ well) from naïve animals were co-cultured with Egmuc-treated BMDC, or incubated only with $100 \mu \mathrm{l}$ of supernatants from Egmuc-treated BMDC, for 4 days at $37^{\circ} \mathrm{C}$. IL-12p40p70 and IFN $\gamma$ levels were tested on culture supernatants by interleukin specific sandwich ELISA assays. Results are expressed in $\mathrm{pg} / \mathrm{ml}$. Activated NK cells were detected by flow cytometry after staining cells with an anti-NK1.1-PE (PK136), anti-CD69-FITC (H1.2F3) and CD49b-APC (DX5), as described above.

\section{Results}

Egmuc peptides induce a Thl-like response. We first analyzed the cellular immunogenicity of a mucin-like peptide derived from E. granulosus (Egmuc) in mice immunized once with Egmuc in Freund's adjuvant. After 10 days of the immunization, cells were obtained from the draining LN and stimulated in vitro with Egmuc, medium or an irrelevant peptide derived from the human mucin MUC6. As depicted in Fig. 1A, immunization with Egmuc induced a strong proliferative $\mathrm{T}$ cell response evaluated by the incorporation of $\left[{ }^{3} \mathrm{H}\right]$-thymidine (CPM). This response was associated to a high production of IFN $\gamma$, while neither IL-5 nor IL-17 was detected.

We sought to determine potential $\mathrm{CD}^{+} \mathrm{T}$ cell epitopes in the Egmuc peptide. Epitope-based vaccines have the ability to focus the immune response on highly antigenic epitopes and are of great importance in the design of cancer vaccines (33). Thus, $\mathrm{CD}^{+} \mathrm{T}$ cell epitopes on Egmuc would be responsible for the type and intensity of the specific immune response generated. We immunized mice with Egmuc in Freund's adjuvant and after 10 days, cells obtained from the draining $\mathrm{LN}$ were stimulated in vitro with a panel of different overlapping peptides spanning the Egmuc sequence (Fig. 1B). The peptides were synthesized as 15 -mers and overlapped by 5 residues. The identification of the $\mathrm{CD}^{+} \mathrm{T}$ cell epitopes was performed by the analysis of the proliferation and IFN $\gamma$ production of cells from draining LN, obtained from C57BL/6 mice immunized with Egmuc or an irrelevant peptide (negative control). The

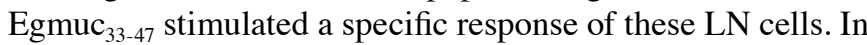


contrast, LN cells from mice immunized with a non-related peptide did not produce IFN $\gamma$ following stimulation with these Egmuc peptides (Fig. 1B).

Following identification of the immunodominant region of Egmuc, the corresponding glycosylated Egmuc peptide carrying the Tn antigen was prepared by solid phase synthesis. We introduced two GalNAc moieties at Ser39 and Thr40, since Tn clusters have been shown to play a critical role in improving both the intensity and the efficiency of the immune response (34). Both Egmuc $_{33-47}$ peptide and glycopeptide were capable of inducing a strong proliferative $\mathrm{T}$ cell response as evaluated by the incorporation of $\left[{ }^{3} \mathrm{H}\right]$-thymidine (CPM) on cells derived from draining $\mathrm{LN}$ of immunized mice. These responses were characterized by a high production of IFN $\gamma$ and low levels of IL-17, in the absence of IL-5 (Fig. 1C).

The Egmuc peptide was also shown to be immunogenic in BALB/c mice, but in this case, the $\mathrm{CD}^{+} \mathrm{T}$ cell epitopes identified belonged to the sequences spanned by Egmuc $_{23-37}$ Egmuc $_{33-47}$ and Egmuc $_{38-52}$ (not shown).

Egmuc-induced antibodies or primed T-cells do not recognize antigens from tumor cell lines. In order to mediate tumor cell killing, antibodies or cytotoxic $\mathrm{T}$ cells must recognize antigens expressed on cancer cells. Thus, we analyzed the ability of Egmuc peptides to induce humoral and cellular immune response that recognize tumor antigens or tumor cells.

The capacity of generated antibodies to recognize native tumor antigens was evaluated on ELISA plates coated with Egmuc peptides or, alternatively, with tumor lysates from the tumor cell lines TA3/Ha and Panc02. The mammary adenocarcinoma cell line TA3/Ha strongly expresses a membrane-associated mucin carrying the Tn antigen (35), while the pancreatic adenocarcinoma cell line Panc02 is known to be reactive to GalNAc-specific lectins (36). IgG antibodies induced by Egmuc peptides or glycopeptide did not recognize antigens from TA3/Ha or Panc02 tumor cell lines nor the glycosylated-Egmuc form, although they were capable of recognizing both the Egmuc or Egmuc E3-47 $_{3}$ peptides (Fig. 2A). Unexpectedly, the glycosylated peptide Egmuc $_{33-47}-2 \mathrm{Tn}$, did not induce antibodies recognizing the peptides or the glycopeptide (Fig. 2A).

We also analyzed the capacity of primed T-cells to respond to stimulation with tumor antigens. When $\mathrm{LN}$ cells from Egmuc-, Egmuc $_{33-47^{-}}$or Egmuc Es-47 $_{37 n}$-immunized mice were incubated with tumor antigens, very low levels of IFN $\gamma$ and undetectable levels of IL-5 or IL-17 were found on culture supernatants, while they recognized Egmuc peptides, as shown by the high levels of IFN $\gamma$ when stimulated in vitro with the corresponding antigen (Fig. 2B).

Overall, these results indicated that Egmuc peptides, although inducing high levels of specific antibodies, hardly recognize tumor-derived antigens. Moreover, in vivo-primed splenocytes cross-reacted at very low levels with antigens present on tumor cells, while they produced very high levels of IFN $\gamma$ in response to stimulation with Egmuc peptides. Thus, Egmuc-specific antibodies or T-cells unlikely would participate in tumor recognition.

In vivo primed-splenocytes with Egmuc peptides contain increased levels of activated NK cells and induce tumor cell
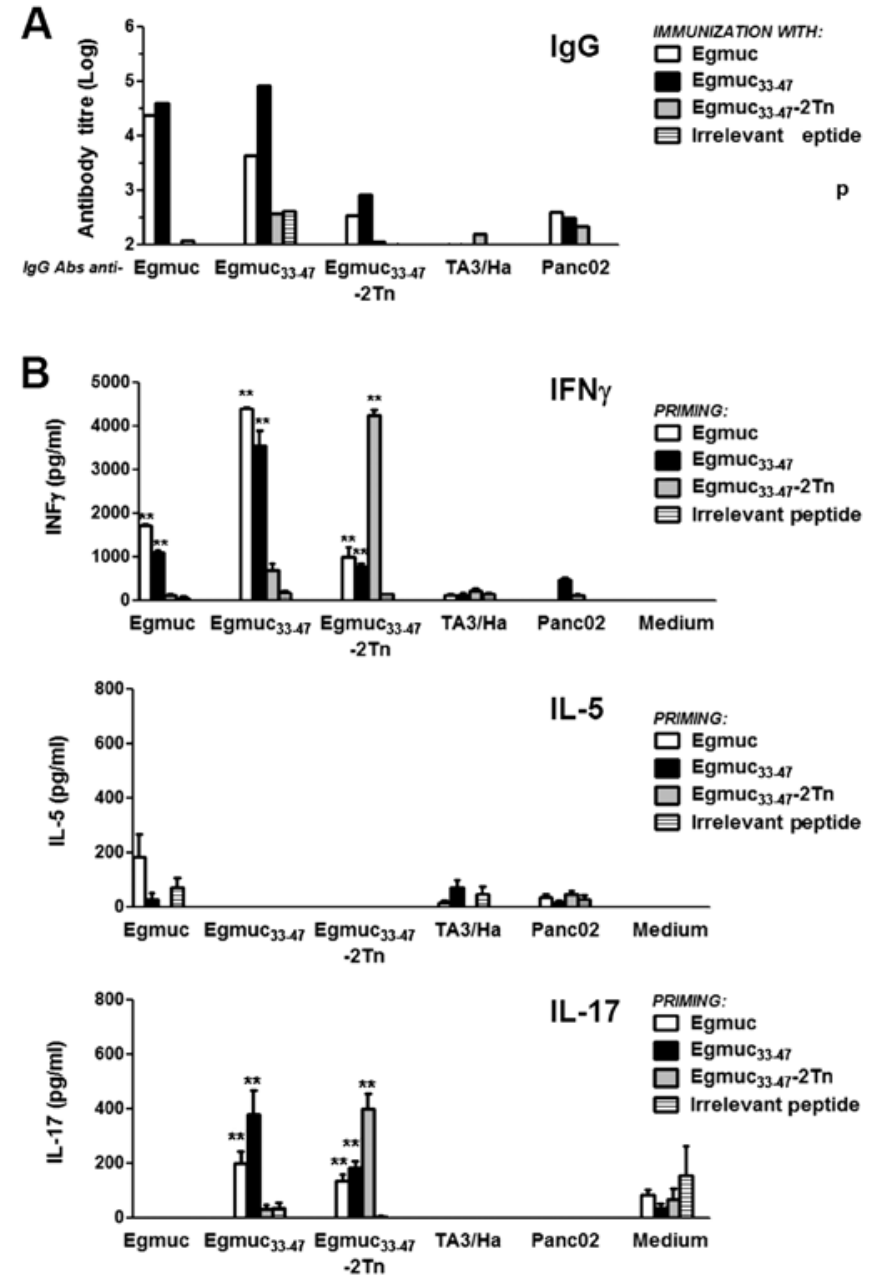

Figure 2. Egmuc-antibodies or in vivo-primed splenocytes do not recognize tumor-derived antigens. (A) C57BL/6 mice (5 per group) were immunized i.p. at days 0, 14, 28 and 42 with Egmuc, Egmuc $_{33-47}$ or Egmuc $_{33-47}-2 \mathrm{Tn}$ (10 nmoles/mouse), as well as PBS (control group) in Freund's adjuvant. Bleeding was carried out at day 49. Specific $\mathrm{IgG}$ antibodies against proteins derived from $\mathrm{TA} 3 / \mathrm{Ha}$ or Panc02 lysates or Egmuc peptides were detected by ELISA. Antibody titers were calculated to be the $\log 10$ highest dilution, which gave twice the absorbance of normal mouse sera diluted 1:100. (B) C57BL/6 mice or BALB/c (4 per group) were immunized i.p. with Egmuc, Egmuc $33-47$ or Egmuc $_{33-47}-2 \mathrm{Tn}$ (10 nmoles/mouse) in CFA. After 10 days, splenocytes of each group were cultured for $72 \mathrm{~h}$ in triplicates in presence of proteins derived from TA3/Ha (for BALB/c) or Panc02 (for C57BL/6) lysates $(150 \mu \mathrm{g}$ ) $\mathrm{ml})$ or Egmuc peptides $(10 \mu \mathrm{g} / \mathrm{ml})$. Culture supernatants were collected and analyzed by ELISA for INF $\gamma$, IL-5 and IL-17 (not shown). Asterisks represent statistically significant differences $\left({ }^{* *} \mathrm{p}<0.01\right)$ with respect to medium.

cytotoxicity in vitro. Tumor cell killing can be mediated by NK cells or cytotoxic T CD8 ${ }^{+}$lymphocytes, as well as by macrophages (37) or $\mathrm{CD}^{+} \mathrm{T}$ cells (38), which can also display cytotoxic properties. In order to study whether Egmuc peptides could modify the levels of these or other cell types, we carried out an extensive phenotyping of splenocytes from immunized mice. The number of $\mathrm{CD} 11 \mathrm{c}^{+}, \mathrm{CD} 11 \mathrm{~b}^{+} \mathrm{F} 4 / 80^{+}, \mathrm{Ly}_{6 \mathrm{G}}{ }^{+} \mathrm{Ly}_{6 \mathrm{C}^{+}}$

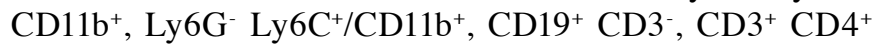
$\mathrm{CD}^{-}{ }^{-}, \mathrm{CD}^{+} \mathrm{CD}^{+} \mathrm{CD}^{-} 9^{-}, \mathrm{CD}^{+} \mathrm{CD}^{+} / \mathrm{CD} 5^{+} \mathrm{FoxP}^{+}$or $\mathrm{NK} 1.1^{+} \mathrm{CD} 49 \mathrm{~b}^{+}$cells was not modified in Egmuc-primed mice as compared to spleens of mice immunized only with the adjuvant (data not shown). However, CD69 ${ }^{+} / \mathrm{NK} 1.1^{+} \mathrm{CD} 49 \mathrm{~b}^{+}$ cells were augmented in spleens of Egmuc-immunized mice (Fig. 3A). 

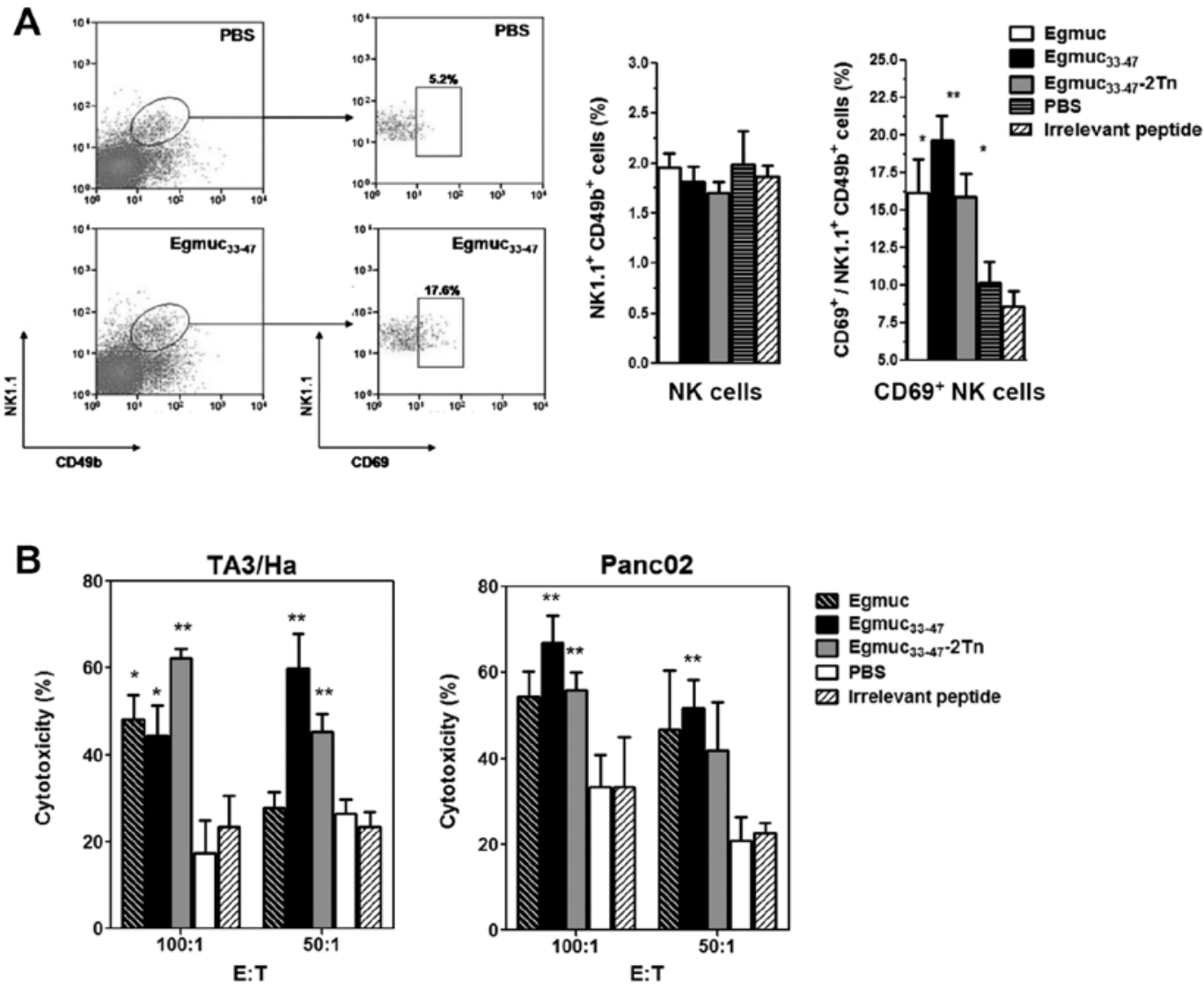

Figure 3. In vivo primed-splenocytes with Egmuc peptides show augmented levels of activated NK cells and mediate cytotoxicity in vitro. (A) C57BL/6 mice (4 per group) were immunized i.p, at days 0, 14 and 28 with Egmuc, Egmuc $33-47$ or Egmuc $_{33-47}-2 \mathrm{Tn}$ ( $20 \mu \mathrm{g} / \mathrm{mouse}$ ), as well as PBS (control group) in Freund's adjuvant. At day 35, spleen cells were stained with anti-CD69, -NK1.1 and -CD49b fluorochrome-conjugated specific antibodies and analyzed by flow cytometry. Thirty thousand events were collected and gated on FSC vs SSC dot plot. NK cells are shown as the percentage of cells in the spleen, while activated NK cells are expressed as the percentage of NK cells co-expressing the CD69 ${ }^{+}$activation marker. Percentage of cells is expressed as mean value of triplicates $( \pm \mathrm{SD}$, indicated by error bars) and are representative of two different experiments. (B) C57BL/6 or BALB/c mice (4 per group) were immunized i.p. with Egmuc, Egmuc $33-47$ or Egmuc $33-47-2 \mathrm{Tn}$ (10 nmoles/mouse) in CFA. After 10 days, splenocytes (E, effector cells) of each group were cultured overnight in triplicates in the presence of different ratios of TA3/Ha or Panc02 tumor cells (T, target cells). Then, $10 \mu 1 /$ well of WST-8 (2-(2-methoxy-4-nitrophenyl)-3-(4nitrophenyl)-5-(2,4-disulfophenyl)-2H-tetrazolium) was added and incubated for $3 \mathrm{~h}$. WST-8 binding to NADPH was followed by absorbance measurement at $450 \mathrm{~nm}$. Results are expressed as mean value of triplicates $( \pm \mathrm{SD}$, indicated by error bars) and are representative of two different experiments. Asterisks represent statistically significant differences ( $\left(\mathrm{p}<0.05,{ }^{* *} \mathrm{p}<0.01\right)$ with respect to mice injected with PBS (control).

Then, we investigated whether in vivo-primed splenocytes can mediate killing of tumor cells. Splenocytes (effector cells) from mice immunized at days 0,14 and 28 were co-cultured with TA3/Ha or Panc02 tumor cells (target cells) at different cell ratios. Egmuc peptide or glycopeptide-primed splenocytes were able to mediate TA3/Ha or Panc02 cell cytotoxicity (Fig. 3B). This result together with the increase of activatedNK cells in the spleen of immunized mice, suggests that activated NK cells might be responsible for mediating tumor cell killing.

Egmuc peptides are internalized and synergize with LPS to induce maturation of DCs. Due to their unique capacity to trigger innate-lymphocyte functions, such as NK cells, we investigated whether DC could be responsible of the increase in $\mathrm{CD} 9^{+} \mathrm{NK}$ cells in the spleens of immunized mice. We first evaluated whether DC uptake of the Egmuc peptides occurs at different levels. To this end, we subjected BMDCs to $1 \mathrm{~h}$ pulses with Atto-647N-labeled Egmuc peptides. Internalization was analyzed by either flow cytometry or confocal microscopy.
Egmuc peptides and glycopeptide were similarly taken up by DCs (Fig. 4A) and colocalized with the late endosome/ lysosome marker Lamp-1, suggesting that the three evaluated peptides are delivered into the cell endosomal compartments for antigen degradation and presentation with MHC class II molecules (Fig. 4B).

We then evaluated whether the Egmuc (glyco)peptides influenced DCs maturation induced by LPS. For this purpose, BMDCs were pulsed with different concentrations of the three Egmuc peptides and we evaluated the expression of co-stimulatory markers and the production of IL-6, IL-10 or IL-12p40p70 in the culture supernatants. When incubated alone, Egmuc peptides did not modify either the expression of CD40, CD80, CD86 MHC class II molecules (not shown), nor the production of the evaluated cytokines (Fig. 4C). Nevertheless, when incubated $2 \mathrm{~h}$ before LPS, the level of IL-6 and specially the level of IL-12p40p70, were considerable augmented, while a decrease of IL-10 was detected (Fig. 4C), suggesting that Egmuc peptides synergize with LPS to induce BMDC maturation. 
A

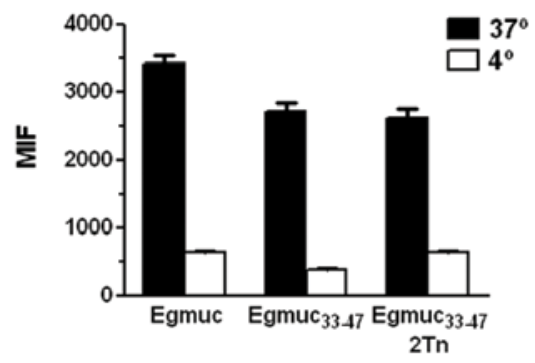

B
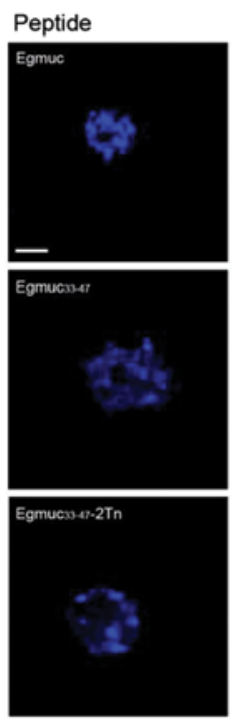

IL-6
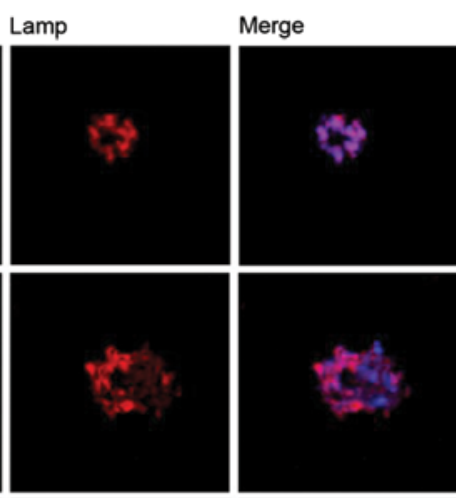

Orthogonal Views
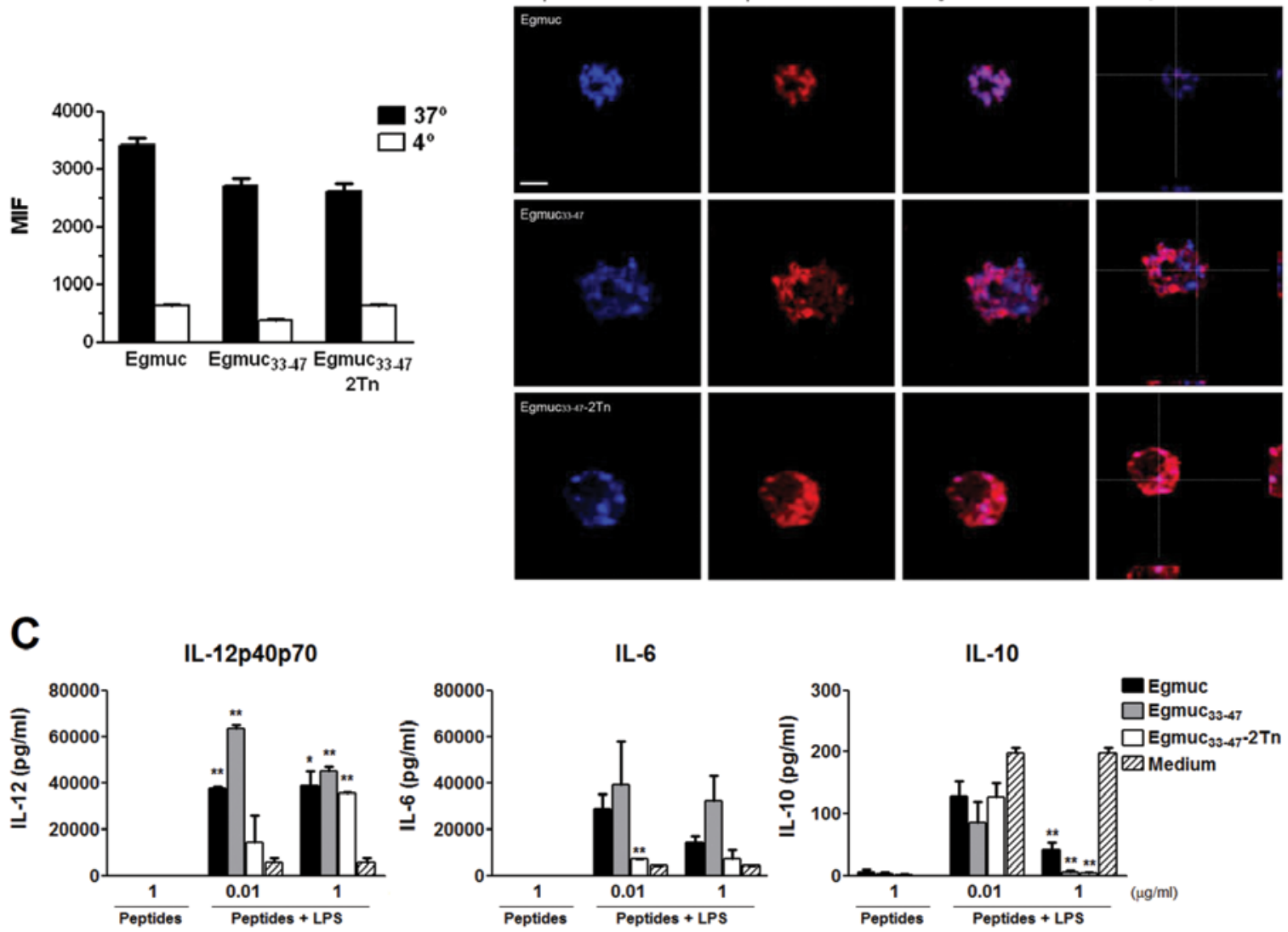

Figure 4. Egmuc peptides are internalized and synergize with LPS to induce maturation of DCs producing higher levels of pro-inflammatory cytokines. Egmuc, Egmuc $_{33-47}$ or Egmuc ${ }_{33-47^{-2}} \mathrm{Tn}$ were conjugated with Atto-647N (blue) and cultured with BMDC in a final concentration of $10 \mu \mathrm{M}$ for $1 \mathrm{~h}$ at $37^{\circ} \mathrm{C}$. BMDCs were then collected and either analyzed by flow cytometry (A) or incubated with an anti-Lamp-1 antibody followed by a TRITC conjugated secondary antibody (red) and images were taken using confocal microscopy (B). Representative confocal micrographs are shown (scale bar, $5 \mu \mathrm{m}$ ). (C) BMDCs were cultured in the presence of Egmuc, Egmuc $33-47$ or $\operatorname{Egmuc}_{33-47^{-}}-2 \mathrm{Tn}(0.01$ or $1 \mu \mathrm{g} / \mathrm{ml})$ with or without LPS $(1 \mu \mathrm{g} / \mathrm{ml})$ for $24 \mathrm{~h}$ at $37^{\circ} \mathrm{C}$. Then, culture supernatants were collected and analyzed by ELISA for IL-6, IL-12p40p70 and IL-10. Results are expressed as mean value of triplicates ( \pm SD, indicated by error bars) and are representative of two different experiments. Asterisks represent statistically significant differences $\left({ }^{*} \mathrm{p}<0.05,{ }^{* *} \mathrm{p}<0.01\right)$ with respect to LPS alone.

Soluble products from DCs activated with Egmuc peptides plus LPS induce in vitro activation of NK cells. The activation of NK cells by DCs represents a pathway which may be important in directly mediating NK cell-dependent antitumor effects. In order to determine whether DCs activated with Egmuc peptides together with LPS, as well as their soluble products, could induce activation of NK cells, we co-cultured BMDCs previously incubated with Egmuc peptides followed by LPS, with splenocytes, or with their derived products. We found a considerable increase of CD69 $9^{\text {hi }} / \mathrm{CD} 49 \mathrm{~b}^{+} \mathrm{NK} 1.1^{+}$cells in splenocytes incubated with culture media derived from BMDCs loaded with Egmuc, Egmuc ${ }_{33-47}$, Egmuc $_{33-47}-2 \mathrm{Tn}$ peptides, as compared to culture media from BMDC incubated with LPS alone (Fig. 5A). In addition, in these conditions, we observed increased levels of IL-12p40p70 and IFN $\gamma$ (Fig. 5B). On the other hand, no significant difference was detected in splenocytes stimulated with BMDCs, or BMDC-derived products, previously loaded with peptides in absence of LPS (Fig. 5). These results suggest that soluble factors produced by BMDCs are sufficient for NK activation in vitro.

\section{Discussion}

Data reporting the antitumor effects of parasite infections are increasing. Indeed, several reports have demonstrated the induction of antitumor immunity by parasites and a prolonged survival of tumor-bearing mice. Recent results indicated that tumor protection can be achieved through the induction of both innate and adaptive antitumor responses, as has been shown for the malaria parasite infection (5) or by intratumoral injection of attenuated Toxoplasma gondii (39). In the present study we evaluated and compared the capacity of an E. granulosus-derived mucin-like peptide to induce antitumor immune activity. We show that, when administered into mice, the three Egmuc peptides conferred splenocytes the ability to kill tumor cells. Also, this cytotoxic activity was correlated with an increased number of activated-NK cells in the spleen of immunized mice, suggesting that these peptides from E. granulosus would activate the innate arm of the immune response that may be efficient for eliminating tumor cells. 
A

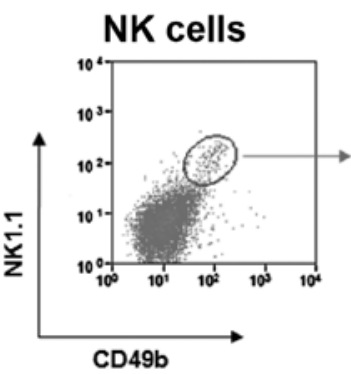

CD69hi NK cells

Gating
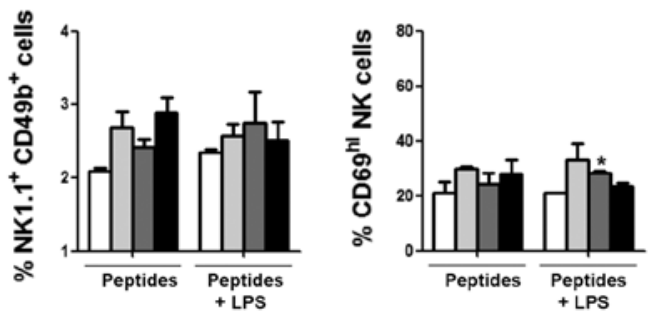

BMDCs
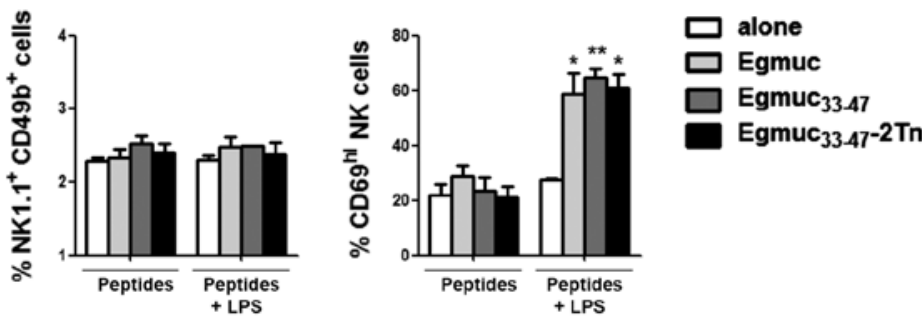

Supernatant

B

IL-12

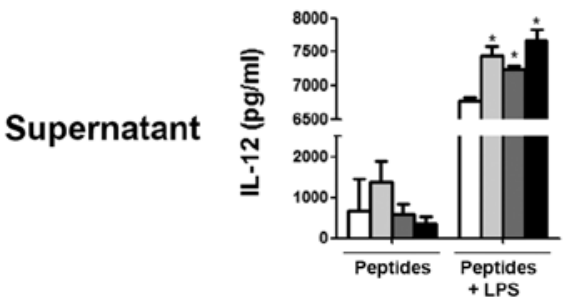

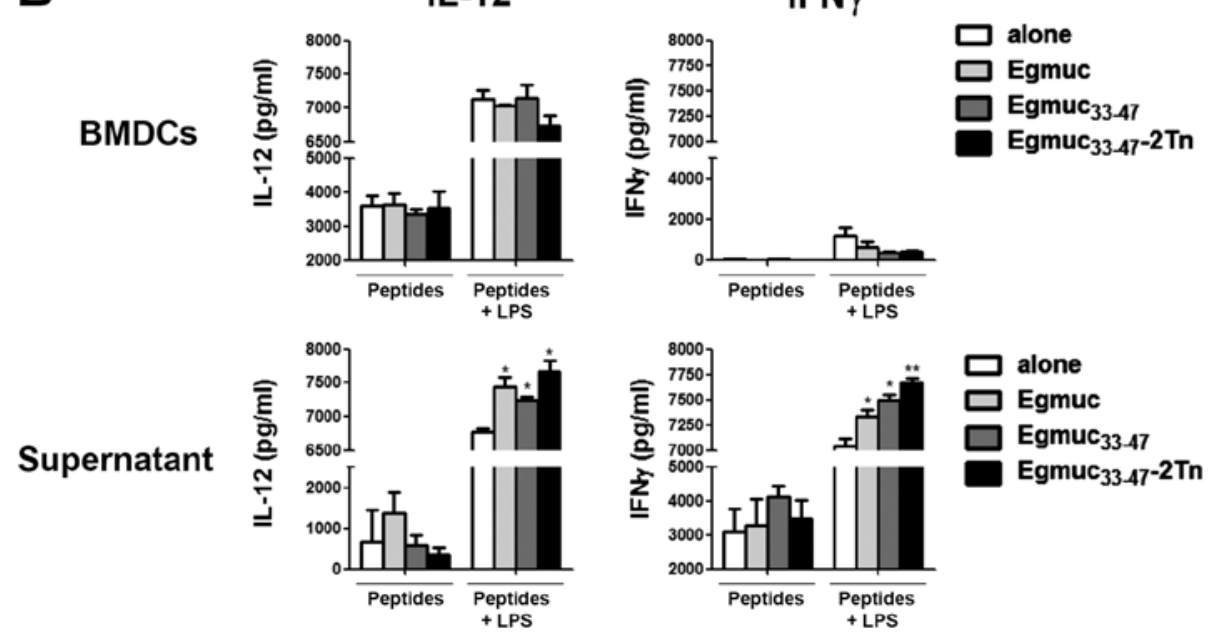

$\square$ alone

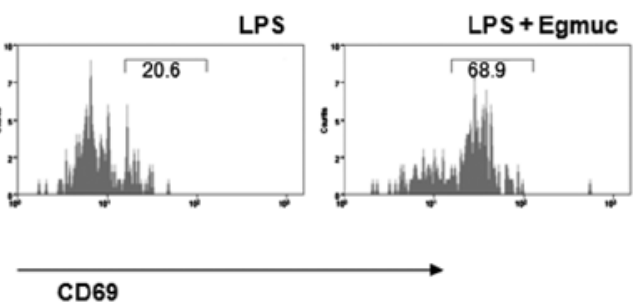

$\square$ Egmuc

$\square$ Egmuc $_{3347}$

$\square$ Egmuc $_{33-47^{-2}}$ Tn

Figure 5. Egmuc-treated DCs induce an increase of CD69 expression on NK cells, probably by DC-derived factors. BMDCs were cultured in the presence of Egmuc, Egmuc ${ }_{33-47}$ or Egmuc Eg3-47 $^{-2 \mathrm{Tn}}$ followed by LPS $(1 \mu \mathrm{g} / \mathrm{ml})$ for $24 \mathrm{~h}$ at $37^{\circ} \mathrm{C}$. Then, they were washed and co-cultured in the presence of splenocytes for 3 days at $37^{\circ} \mathrm{C}$ (left). Alternatively, culture supernatants from Egmuc-treated BMDC were added to splenocytes and cultured for 3 days at $37^{\circ} \mathrm{C}$. Cells were collected and incubated with an anti-CD69, -NK1.1 and -CD49b fluorochrome-conjugated specific antibodies and analyzed by flow cytometry. Twenty thousand events were collected and gated on FSC vs SSC dot plot (A). The levels of IL-12p40p70 and IFN $\gamma$ (B) were analyzed by ELISA on culture supernatants. Results are expressed as mean value of triplicates $( \pm \mathrm{SD}$, indicated by error bars) and are representative of two different experiments. Asterisks represent statistically significant differences $\left(\mathrm{p}<0.05,{ }^{* *} \mathrm{p}<0.01\right)$ with respect to the condition in the absence of peptides (LPS alone).

NK cells have been shown to have an important role in antitumor immune response. For instance, patients with lung cancer who have a high level of NK cell infiltration in the tumor, have better prognosis than those with a low level of NK cells (40). NK-cell activation is controlled by the dynamic balance between activating and inhibitory signals. The battery of receptors possessed by NK cells helps mediate the detection of tumor or infected cells and embark on the signaling pathways necessary to eliminate them (41). NK-cell effector functions can also be stimulated through DC-derived signals via cytokines and cell contact (42). Indeed, several studies have already shown the activation, 
both phenotypically and functionally, of NK cells by DCs in response to different microbial stimuli, such as reovirusinfected human melanoma cells (43), inactivated influenza virus (44), adenovirus encoding melanoma tumor antigens (45), as well as TLR ligands (44), by mechanisms involving cell contact and secretion of DC-derived cytokines.

Considering the role of DCs in stimulating NK cell activation, we sought to evaluate whether DCs treated with Egmuc peptides could activate NK cells. First, we found that Egmuc peptides and Tn-glycopeptide synergize with LPS-induced maturation of DCs, inducing the production of higher levels of IL-12 and IL-6, in the absence of the regulatory cytokine IL-10. Then, we evaluated whether cytokines produced by Egmuc-treated-BMDCs (such as IL-12), or DC-NK contact interactions might activate NK cells in vitro. We co-cultured Egmuc-treated BMDCs with splenocytes, or alternatively, splenocytes cultured in the presence of BMDC-derived soluble factors only. The NK cells from splenocytes incubated with soluble factors from loaded-BMDCs presented a more activated phenotype, defined by an increase in CD69 expression, as compared to splenocytes incubated with BMDCs stimulated with LPS only, indicating that DC-derived products, are sufficient for NK activation. Whether NK activation detected by an increase of CD69 expression, is responsible for the in vitro cell cytotoxicity by splenocytes from Egmuc-immunized mice, or for the increase of activated NK cells in vivo, remains to be explored. Additional cytotoxicity experiments with purified NK cells from immunized mice will give direct evidence of their role in eliminating tumor cells in vivo.

Importantly, the results reported here indicate that the synergic effect of Egmuc peptides on LPS-maturation of DCs, as well as the increase of activated NK cells and cytotoxic activity in the spleens from immunized mice, would rather rely on the Egmuc peptide sequence from E. granulosus that could act as a PAMP. Molecules from different pathogens that induce maturation of DCs have been identified. For example, Schistosoma mansoni adult worm glycolipids interact with DCs and skew $\mathrm{T}$ cell responses towards a Th1 profile, upregulating the production of pro-inflammatory cytokines in an interaction that is mediated by DC-SIGN and TLR4 (46). Also, DCs exposed to Gram-negative bacteria respond by making IL-6, IL-12 and IL-23, which promote the development of naive Th cells into Th1 or Th17 cells (47). Interestingly, several TLR-ligand components from parasites, such as the glycosylphosphatidylinositol of Plasmodium falciparum (48) or $T$. cruzi (49) might be important factors in the induction of pro-inflammatory responses and could be used as adjuvant components to enhance antitumor immune responses (50).

One possibility that could explain the observed synergism is that the interaction of Egmuc peptides with DCs may upregulate TLR4 expression on DCs, leading to an enhanced production of pro-inflammatory cytokines when incubated with LPS. Indeed, it has been reported that many microbial products induced upregulation of several TLRs (51). Thus, we are currently evaluating the expression of TRL4 in BMDC stimulated with Egmuc peptides. Moreover, experiments using TLR knockout mice would bring evidence regarding activation of DCs by Egmuc peptides together with LPS.

Our results indicate that the introduction of the cluster of two Tn moieties displayed on the Egmuc glycopeptides did not confer an advantage for antigen uptake by dendritic cells or for induction of antitumor antibodies. Despite this apparent contradiction, it might be possible that clusters of more than three Tn antigens are needed to induce antibodies capable of recognizing tumor cells (32). Also, the Egmuc B $_{3-47}-2$ Tn glycopeptide induced a cell immune response that did not cross-react with the Egmuc non-glycosylated peptides and very low specific-antibody titres, suggesting that GalNAc linkage to the Egmuc $_{33-47}$ peptide modified its B and T cell immunogenicity. These data, together with other already published (52), indicate that the introduction of glycosylation sites on peptides must be attentively selected since their immunological properties can be markedly modified.

In conclusion, we present data suggesting that mucin-like peptides from parasitic origin might be useful targets for antitumor immunotherapy, since they confer splenocytes the capacity to eliminate tumor cells, through a mechanism that could involve activation of NK cells, in a process mediated soluble DC-derived factors. This constitute, to our knowledge, the first report showing that a single purified peptide of helminth parasite origin induces antitumor activity.

\section{Acknowledgements}

This study was supported by grants from Comisión Honoraria de Lucha contra el Cáncer (Uruguay), International Centre for Genetic Engineering and Biotechnology (Italy), Programme Transversal de Recherche No. 262 Institut Pasteur (France) and Programa Grupos de Investigación (CSIC, Universidad de la República, Uruguay). V.N. was supported by Agencia Nacional de Investigación e Innovación (Uruguay). We thank F. Groh for the amino acid analyses and F. Bonhomme for the mass spectrometry analyses.

\section{References}

1. Ferlay J, Shin HR, Bray F, Forman D, Mathers C and Parkin DM: Estimates of worldwide burden of cancer in 2008: GLOBOCAN 2008. Int J Cancer 127: 2893-2917, 2010.

2. de Martel C, Ferlay J, Franceschi S, et al: Global burden of cancers attributable to infections in 2008: a review and synthetic analysis. Lancet Oncol 13: 607-615, 2012.

3. Benamrouz S, Conseil V, Creusy C, Calderon E, Dei-Cas E and Certad G: Parasites and malignancies, a review, with emphasis on digestive cancer induced by Cryptosporidium parvum (Alveolata: Apicomplexa). Parasite 19: 101-115, 2012.

4. Oliveira EC, Leite MS, Miranda JA, et al: Chronic Trypanosoma cruzi infection associated with low incidence of 1,2-dimethylhydrazine-induced colon cancer in rats. Carcinogenesis 22: 737-740, 2001.

5. Chen L, He Z, Qin L, et al: Antitumor effect of malaria parasite infection in a murine Lewis lung cancer model through induction of innate and adaptive immunity. PLoS One 6: e24407, 2011.

6. Wang XL, Fu BQ, Yang SJ, et al: Trichinella spiralis - a potential antitumor agent. Vet Parasitol 159: 249-252, 2009.

7. Akgül H, Tez M, Unal AE, Keşkek M, Sayek I and Ozçelik T: Echinococcus against cancer: why not? Cancer Immunol Immunother 98: 1999-2000, 2003.

8. Darani HY and Yousefi M: Parasites and cancers: parasite antigens as possible targets for cancer immunotherapy. Future Oncol 8: 1529-1235, 2012.

9. Yousofi Darani H, Soozangar N, Khorami S, Taji F, Yousofi M and Shirzad H: Hydatid cyst protoscolices induce cell death in WEHI-164 fibrosarcoma cells and inhibit the proliferation of baby hamster kidney fibroblasts in vitro. J Parasitol Res 304183: January 31, 2012. doi: 10.1155/2012/304183.

10. Medzhitov R: Recognition of microorganisms and activation of the immune response. Nature 449: 819-826, 2007. 
11. Palucka AK, Ueno H, Fay JW and Banchereau J: Taming cancer by inducing immunity via dendritic cells. Immunol Rev 220 : 129-150, 2007.

12. Correale $\mathbf{J}$ and Farez M: Helminth antigens modulate immune responses in cells from multiple sclerosis patients through TLR2-dependent mechanisms. J Immunol 183: 5999-6012, 2009.

13. Elliott DE and Weinstock JV: Helminth-host immunological interactions: prevention and control of immune-mediated diseases. Ann NY Acad Sci 1247: 83-96, 2012.

14. van Vliet, SJ, van Liempt E, Saeland E, et al: Carbohydrate profiling reveals a distinctive role for the C-type lectin MGL in the recognition of helminth parasites and tumor antigens by dendritic cells. Int Immunol 17: 661-669, 2005.

15. Vanhoutte F, Breuilh L, Fontaine J, et al: Toll-like receptor (TLR) 2 and TLR 3 sensing is required for dendritic cell activation, but dispensable to control Schistosoma mansoni infection and pathology. Microbes Infect 9: 1606-1613, 2007.

16. Cummings RD and Nyame AK: Schistosome glysoconjugates. Biochim Biophys Acta 1455: 363-374, 1999.

17. Doedens A, Loukas A and Maizels RM: A cDNA encoding Tc-MUC-5, a mucin from Toxocara canis larvae identified by expression screening. Acta Trop 79: 211-217, 2001.

18. Theodoropoulos G, Hicks SJ, Corfield AP, Miller BG and Carrington SD: The role of mucins in host-parasite interactions: Part II - helminth parasites. Trends Parasitol 17: 130-135, 2001.

19. Thomas PG and Harn DAJ: Immune biasing by helminth glycans Cell Microbiol 6: 13-22, 2004

20. Alvarez Errico D, Medeiros A, Míguez M, et al: O-glycosylation in Echinococcus granulosus: identification and characterization of the carcinoma-associated Tn antigen. Exp Parasitol 98 100-109, 2001

21. Brockhausen I: Mucin-type $O$-glycans in human colon and breas cancer: glycodynamics and functions. EMBO Rep 7: 599-604, 2006.

22. Schietinger A, Philip M, Yoshida BA, Azadi P, Liu H, Meredith SC and Schreiber H: A mutant chaperone converts a wild-type protein into a tumor-specific antigen. Science 314: 304-308, 2006

23. Baldus SE, Engelmann K and Hanisch FG: MUC1 and the MUCs: a family of human mucins with impact in cancer biology. Crit Rev Clin Lab Sci 41: 189-231, 2004.

24. Carraway KL III, Funes M, Workman HC and Sweeney C: Contribution of membrane mucins to tumor progression through modulation of cellular growth signaling pathways. Curr Top Dev Biol 78: 1-22, 2007.

25. Freire T and Osinaga E: The sweet side of tumor immunotherapy. Immunotherapy 4: 719-734, 2012.

26. Kufe DW: Mucins in cancer: function, prognosis and therapy. Nat Rev Cancer 9: 874-885, 2009.

27. Beatson RE, Taylor-Papadimitriou J and Burchell JM: MUC1 immunotherapy. Immunotherapy 2: 305-327, 2010.

28. Quoix E, Ramlau R, Westeel V, et al: Therapeutic vaccination with TG4010 and first-line chemotherapy in advanced nonsmall-cell lung cancer: a controlled phase 2B trial. Lancet Oncol 12: 1125-1133, 2011

29. Slovin SF, Ragupathi G, Musselli C, et al: Fully synthetic carbohydrate-based vaccines in biochemically relapsed prostate cancer: clinical trial results with alpha-N-acetylgalactosamine-O-serine/ threonine conjugate vaccine. J Clin Oncol 21: 4292-4298, 2003.

30. Fernandez C, Gregory WF, Loke P and Maizels RM: Fulllength-enriched cDNA libraries from Echinococcus granulosus contain separate populations of oligo-capped and trans-spliced transcripts and a high level of predicted signal peptide sequences. Mol Biochem Parasitol 122: 171-180, 2002.

31. Coïc YM, Lan CL, Neumann JM, Jamin N and Baleux F: Slightly modifying pseudoproline dipeptides incorporation strategy enables solid phase synthesis of a 54 AA fragment of caveolin-1 encompassing the intramembrane domain. J Pept Sci 16: 98-104, 2010.

32. Lo-Man R, Vichier-Guerre S, Perraut R, et al: A fully synthetic therapeutic vaccine candidate targeting carcinoma-associated Tn carbohydrate antigen induces tumor-specific antibodies in nonhuman primates. Cancer Res 64: 4987-4994, 2004.
33. Rosa DS, Ribeiro SP and Cunha-Neto E: CD4 ${ }^{+} \mathrm{T}$ cell epitope discovery and rational vaccine design. Arch Immunol Ther Exp 58: 121-130, 2010

34. Lo-Man R, Vichier-Guerre S, Bay S, Deriaud E, Cantacuzene D and Leclerc C: Antitumor immunity provided by a synthetic multiple antigenic glycopeptide displaying a tri-Tn glycotope J Immunol 166: 2849-2854, 2001.

35. Singhal AK: Histo-blood group antigens in cancer. Semin Cancer Biol 2: 379-388, 1991.

36. Singh SK, Streng-Ouwehand I, Litjens M, et al: Characterization of murine MGL1 and MGL2 C-type lectins: distinct glycan specificities and tumor binding properties. Mol Immunol 46: 1240-1249, 2009.

37. Hubert P, Heitzmann A, Viel S, et al: Antibody-dependent cell cytotoxicity synapses form in mice during tumor-specific antibody immunotherapy. Cancer Res 71: 5134-5143, 2011.

38. Quezada SA, Simpson TR, Peggs KS, et al: Tumor-reactive CD4(+) T cells develop cytotoxic activity and eradicate large established melanoma after transfer into lymphopenic hosts. J Exp Med 207: 637-650, 2010.

39. Baird JR, Byrne KT, Lizotte PH, et al: Immune-mediated regression of established B16F10 melanoma by intratumoral injection of attenuated Toxoplasma gondii protects against rechallenge. J Immunol 190: 469-478, 2013.

40. Villegas FR, Coca S, Villarrubia VG, et al: Prognostic significance of tumor infiltrating natural killer cells subset CD57 in patients with squamous cell lung cancer. Lung Cancer 35: 23-28, 2002.

41. Malhotra A and Shanker A: NK cells: immune cross-talk and therapeutic implications. Immunotherapy 3: 1143-1166, 2011.

42. Walzer T, Dalod M, Robbins SH, Zitvogel L and Vivier E: Natural-killer cells and dendritic cells: 'l'union fait la force'. Blood 106: 2252-2258, 2005.

43. Prestwich RJ, Errington F, Steele LP, et al: Reciprocal human dendritic cell-natural killer cell interactions induce antitumor activity following tumor cell infection by oncolytic reovirus. J Immunol 183: 4312-4321, 2009.

44. Gerosa F, Gobbi A, Zorzi P, et al: The reciprocal interaction of NK cells with plasmacytoid or myeloid dendritic cells profoundly affects innate resistance functions. J Immunol 174: 727-734, 2005.

45. Blalock LT, Landsberg J, Messmer M, et al: Human dendritic cells adenovirally-engineered to express three defined tumor antigens promote broad adaptive and innate immunity. Oncoimmunology 1: 287-357, 2012.

46. van Die I, van Stijn CM, Geyer H and Geyer R: Structural and functional analysis of glycosphingolipids of Schistosoma mansoni. Methods Enzymol 480: 117-140, 2010.

47. Truchetet ME, Beven L, Renaudin H, et al: Potential role of Mycoplasma hominis in interleukin (IL)-17-producing CD4 ${ }^{+}$ T-cell generation via induction of IL-23 secretion by human dendritic cells. J Infect Dis 204: 1796-1805, 2011.

48. Gowda DC: TLR-mediated cell signaling by malaria GPIs. Trends Parasitol 23: 596-604, 2007.

49. Campos MA, Almeida IC, Takeuchi O, et al: Activation of Toll-like receptor-2 by glycosylphosphatidylinositol anchors from a protozoan parasite. J Immunol 167: 416-423, 2001.

50. Junqueira C, Guerrero AT, Galvão-Filho B, et al: Trypanosoma cruzi adjuvants potentiate $\mathrm{T}$ cell-mediated immunity induced by a NY-ESO-1 based antitumor vaccine. PLoS One 7: e36245, 2012.

51. Tarang S, Kumar S and Batra SK: Mucins and toll-like receptors: kith and kin in infection and cancer. Cancer Lett 321: 110-119, 2012.

52. Freire T, Lo-Man R, Bay S and Leclerc C: Tn glycosylation of the MUC6 protein modulates its immunogenicity and promotes the induction of Th17-biased T cell responses. J Biol Chem 286: 7797-7811, 2011. 